\title{
Refractory nonconvulsive status epilepticus in coma: analysis of the evolution of ictal patterns
}

\author{
Estado de mal epiléptico não convulsivo refratário no coma: análise da evolução dos \\ padrões ictais
}

Paulo Breno Noronha Liberalesso, Eliana Garzon, Elza Marcia T. Yacubian, Américo C. Sakamoto

\begin{abstract}
Objective: Nonconvulsive status epilepticus (NCSE) is currently considered as one of the most frequent types of status epilepticus (SE). The objective of the present study was to identify the natural history of the electrographical evolution of refractory NCSE and to establish the relationship between ictal patterns and prognosis. Methods: We analyzed, retrospectively, 14 patients with loss of consciousness and NCSE. The ictal patterns were classified as discrete seizures (DS), merging seizures (MS), continuous ictal discharges (CID), continuous ictal discharges with flat periods (CID-F), and periodic lateralized epileptiform discharges (PLEDs). Results: The ictal patterns were DS ( $n=7 ; 50.0 \%$ ), PLEDs ( $n=3 ; 1.4 \%), \operatorname{CID}(n=2 ; 14.3 \%)$, MS ( $n=1 ; 7.1 \%)$, and CID-F ( $n=1 ; 7.1 \%)$. Conclusions: NCSE electrographic findings are heterogeneous and do not follow a stereotyped sequence. PLEDs were related to a higher probability of neurological morbidity and mortality.
\end{abstract}

Key words: nonconvulsive status epilepticus, ictal patterns, PLEDs.

RESUMO

Objetivo: Estado de mal epiléptico não convulsivo (EMENC) é atualmente considerado uma das formas mais frequentes de estado de mal epiléptico. O objetivo deste estudo foi identificar a história natural da evolução eletrográfica do EMENC refratário, bem como estabelecer relações entre padrões ictais e o prognóstico. Métodos: Foram analizados, retrospectivamente, 14 pacientes com comprometimento da consciência e EMENC. Os padrões ictais foram classificados em crises isoladas (CI), crises subintrantes (CS), descarga ictal contínua (DIC), descarga ictal contínua com períodos de atenuação (DIC-A) e descargas epileptiformes periódicas lateralizadas (PLEDs). Resultados: Os padrões ictais observados foram CI ( $n=7 ; 50,0 \%)$, PLEDs ( $n=3 ; 1,4 \%)$, DIC ( $n=2 ; 14,3 \%)$, CS ( $n=1 ; 7,1 \%)$ e DIC-A ( $n=1 ; 7,1 \%)$. Conclusões: Achados eletrográficos no EMENC refratário são heterogêneos e não obedecem a uma sequência estereotipada. As PLEDs estão associadas à maior probabilidade de morbidade e mortalidade neurológica.

Palavras-Chave: estado de mal epiléptico não convulsivo, padrões ictais, PLEDs.

An epileptic seizure represents a short-term, isolated and self-limited episode, characterized by synchronous and abnormal depolarization of a given group of cortical neurons. Occasionally, central inhibitory mechanisms become unable to abort this phenomenon, giving rise to a neurological condition defined as status epilepticus (SE).

In the early sixties, SE was defined as an epileptic seizure, which, due to its prolonged action and frequent recurrence, generates a fixed epileptic condition ${ }^{1}$. Later, the definitions proposed by the Committee for the Classification and Terminology of the International League against Epilepsy did not establish a seizure time for a definitive diagnosis of $\mathrm{SE}^{2,3}$.
Thus, several definitions can be found in the literature, and an operational definition was adopted. For most investigators, the SE is a single epileptic seizure or recurrent seizures without recovery of consciousness lasting at least 30 minutes $^{4,5}$.

In 1962, at the "X European Conference of Epileptology and Clinical Neurophysiology", SE was first subdivided into a convulsive and a nonconvulsive form ${ }^{1}$. The nonconvulsive SE (NCSE) is a heterogeneous and controversial entity ${ }^{6,7}$. Within this group, the term absence SE or petit mal status is usually used for those patients with generalized electroencephalography (EEG) findings, who are ambulatory and may appear confused, while those with a partial EEG onset have been

Hospital São Paulo, Federal University of São Paulo, Escola Paulista de Medicina, São Paulo SP, Brazil.

Correspondence: Paulo Breno Noronha Liberalesso; Rua Benjamin Constant 90 / apto. 73; 80060-020 Curitiba PR - Brasil;

E-mail: paulo.neuroped@gmail.com

Conflict of interest: There is no conflict of interest to declare.

Received 07 November 2011; Received in final form 30 January 2012; Accepted 08 February 2012 
described as complex partial SE. The term NCSE is more often applied to patients who are severely obtunded or comatose with minimal or no motor movements, often with serious medical condition. However, NCSE definition is not straightforward and some investigators have used NCSE to include all conditions ranging from those with barely detectable mental status changes to coma.

In the present paper, we have discussed the evaluative ictal patterns of patients with refractory NCSE in those who are comatose. The objective of the study was to identify the natural history of the electrographical evolution of patients with refractory NCSE in coma, as well as the possible relationship between ictal patterns and short-term prognosis, regarding neurological sequels and mortality. The study was approved by the Ethics and Human Research of the Hospital São Paulo, at the Federal University of São Paulo.

\section{METHODS}

All patients with NCSE were selected by a retrospective analysis of the medical records of Hospital São Paulo, Federal University of São Paulo, Escola Paulista de Medicina, and Hospital Alemão Oswaldo Cruz, from January 2001 and June 2004. This study was approved by the Ethical Committee No. 1312/02.

NCSE was defined as an episode lasting at least 30 minutes and characterized by unexplained decreased consciousness level, stupor or coma with or without subtle motor manifestations presenting an electrographical pattern. This pattern consisted of at least one criterion:

- repetitive, focal or generalized spikes, sharp waves, spikeand-wave or sharp-and-slow wave complexes at a frequency of $>3 / \mathrm{s}$;

- sequential rhythmic waves with evolution of ictal pattern, such as incrementing onset with increase in voltage and/ or increase or slowing of frequency and/or decrementing offset with decrease in voltage or frequency and/or postdischarge slowing or voltage attenuation;

- periodic epileptiform discharges, lateralized or generalized with features suggesting ictal pattern that consist of increase or decrease in the period duration, and ictal pattern evolving from periodicity ${ }^{8}$.

All ictal patterns were classified, as proposed by Treiman et al. ${ }^{9}$, in discrete seizures (DS), merging seizures (MS), continuous ictal discharge (CID), CID with flat periods (CID-F), and periodic lateralized epileptic discharges (PLEDs).

Besides clinical condition and electrographical pattern, the inclusion criteria were NCSE submitted to continuous electroencephalographic monitoring or daily serial electroencephalographic recordings lasting at least 30 minutes between the time of SE diagnosis and SE resolution or death.
For inclusion, NCSE has to be considered refractory and it did not respond to intravenous administration of at least two first- and second-line antiepileptic drugs, such as benzodiazepines, phenobarbital, and phenytoin.

NCSE characterized by absent seizures or repetitive complex partial seizure with a slight change in the level of consciousness was excluded, with significant improvement in clinical state and baseline EEG after administration of first and second line antiepileptic drugs.

All recordings were obtained with a 21-channel Nihon Koden instrument, electrodes were positioned according to the 10-20 International System. The sampling method was not used, but all recordings were fully analyzed by two independent investigators.

After the electrographic recordings evaluation, previously elaborated protocols were filled out by the same investigator, for each patient. One patient was excluded from the study due to the impossibility of adequate classification of SE on the basis of the data contained in the medical records.

\section{RESULTS}

Fourteen patients with NCSE (six of them males, 42.9\%) aged 1 to 84 years-old (mean of 44.1 years-old) were evaluated (Table). Six (42.9\%) patients had previous symptomatic focal epilepsy. Regarding the etiology of SE, there was a predominance of metabolic disorders $(n=3 ; 21.4 \%)$ and septicemia $(n=5 ; 35.7 \%)$, with one case of meningitis, one of neurocysticercosis, one of cranioencephalic traumatic injury, one of ischemic cerebrovascular accident in the acute phase, one of acute respiratory insufficiency, one of postvaccinal encephalitis, and one of previous symptomatic focal epilepsy out of control. In one $(9.1 \%)$ elderly patient, who had never had an epileptic seizure and who, according to his relatives, had been in good health until the time of SE, it was not possible to identify the etiology (Table).

All patients, except the one with undetermined etiology - who died before being subjected to complete neurological examination -, were submitted to neuroimaging exams, with computed axial tomography (CT) of the skull in five and CT plus nuclear magnetic resonance of the brain in eight. Two of the patients investigated presented normal neuroimaging exams and three, chronic changes exclusively related to age (diffuse cortical and subcortical atrophy). In one patient in the advanced stage of acquired immunodeficiency syndrome, the CT scan revealed an extensive and expansive cerebral lesion located in the roof of the mesencephalon, extensively involving the temporal lobe and the basal nuclei in the left brain hemisphere. The etiology of this lesion could not be determined due to the lack of clinical conditions for a biopsy and refusal of the family to permit an autopsy. 
Table. Demographic data of the patients, previous presence of epilepsy, and etiology of status epilepticus (SE).

\begin{tabular}{|c|c|c|c|c|c|c|c|c|c|c|}
\hline Patient & Sex & $\begin{array}{c}\text { Age } \\
\text { (years) }\end{array}$ & Epilepsy & Etiology of SE & $\begin{array}{l}\text { Initial } \\
\text { pattern }\end{array}$ & $\begin{array}{l}\text { Second } \\
\text { pattern }\end{array}$ & $\begin{array}{l}\text { Third } \\
\text { pattern }\end{array}$ & $\begin{array}{l}\text { Fourth } \\
\text { pattern }\end{array}$ & $\begin{array}{l}\text { Fifth } \\
\text { pattern }\end{array}$ & Outcome \\
\hline 1 & $\mathrm{~F}$ & 7 & - & Cerebral metastasis & DS + PLEDs & - & - & - & - & Death \\
\hline 2 & M & 21 & - & Sepsis metabolic disorder & MS & Control & - & - & - & No sequel \\
\hline 3 & M & 26 & - & $\begin{array}{l}\text { Meningitis structural lesion } \\
\text { of an undetermined nature }\end{array}$ & PLEDs & MS & - & - & - & Death \\
\hline 4 & $\mathrm{~F}$ & 50 & Yes & Sepsis glioblastoma & DS & MS & Control & - & - & No sequel \\
\hline 5 & M & 50 & Yes & Sepsis metabolic disorder & DS & Control & - & - & - & No sequel \\
\hline 6 & $\mathrm{~F}$ & 53 & Yes & $\begin{array}{c}\text { Neurocysticercosis } \\
\text { intracranial hypertension }\end{array}$ & PLEDs & CID & CID-F & DS & so & Death \\
\hline 7 & M & 59 & - & Sepsis metabolic disorder & CID & MS & - & - & - & Death \\
\hline 8 & $\mathrm{~F}$ & 69 & Yes & Sepsis & CID-F & CID & PLEDs & - & - & Death \\
\hline 9 & M & 82 & - & Undetermined & CID & Control & - & - & - & No sequel \\
\hline 10 & $\mathrm{~F}$ & 84 & - & Cranial trauma & PLEDs & MS & - & - & - & Death \\
\hline 11 & F & 84 & - & $\begin{array}{l}\text { Ischemic cerebrovascular } \\
\text { accident }\end{array}$ & DS & CID & - & - & - & Death \\
\hline 12 & $\mathrm{~F}$ & 1 & Yes & $\begin{array}{l}\text { Pneumonia acute respiratory } \\
\text { insufficiency }\end{array}$ & DS & MS & CID & - & - & No sequel \\
\hline 13 & $\mathrm{~F}$ & 23 & No & Postvaccinal encephalitis & DS & MS & - & - & - & Death \\
\hline 14 & M & 9 & Yes & $\begin{array}{c}\text { Decompensation of previous } \\
\text { epilepsy }\end{array}$ & DS & MS & - & - & - & No sequel \\
\hline
\end{tabular}

F: female; M: male; DS: discrete seizures; MS: merging seizures; CID: continuous ictal discharges; CID-F: continuous ictal discharges with flat; PLEDs: periodic lateralized epileptiform discharges; SO: suppression outburst. Note: the electrographic pattern of suppression-outburst is considered to be ictal in rare situations and in determined epileptic syndromes and it was observed in this patient during continuous midazolam infusion. He was included in the table because we believed this would be important for the analysis of the electrographic evolution.

The ictal patterns were sequentially evaluated from the time of diagnosis to the control of SE or to the patient's death. The most frequent initial pattern was DS in seven (50.0\%) cases, followed by PLEDs in three (21.4\%), CID in two (14.3\%), MS in one (7.1\%), and CID-F also in one (7.1\%). In one case, the first electroencephalographic recording revealed the coexistence of two distinct ictal patterns (DS and PLEDs), which change the period at irregular random intervals.

Three $(21.4 \%)$ patients presented only one ictal pattern throughout the evolution of SE, corresponding to the cases of best outcome - without neurological sequels after the control of SE. The complete sequence of the ictal patterns of all patients can be seen in Table.

As to the short-term outcome, eight (57.1\%) patients died during the occurrence of refractory complex partial SE and six $(42.9 \%)$ were discharged from the hospital without additional neurological sequels.

\section{DISCUSSION}

Originally described by Gastaut et al. ${ }^{10}$ and formerly thought to be rare, NCSE is currently one of the most frequent clinical types of $\mathrm{SE}^{11}$. Although it can be subdivided into a continuous type with permanent alteration of consciousness and/or of behavior and a type characterized by recurrent complex partial seizures $^{12}$, many authors believe that they only represent different moments of the same evaluative picture ${ }^{13}$.

NCSE should be a better terminology, but in this category, heterogeneous conditions, such as absence SE, complex partial SE and NCSE, in patients severely ill can raise confusion. An appropriate definition needs to be reviewed because all three clinical conditions can have distinct evolutions, regarding the morbidity and mortality as well response to anti-epileptic drugs (AED). 
Considering only refractory NCSE, we selected the more severe cases with patients in coma. Therefore, for a better distinction of this particular clinical condition, we denominated NCSE in coma.

A more detailed discussion about the terminology deserves to be carried out. The term NCSE should be applied to patients who are severely obtunded or comatose with minimal or no motor movements, often with medical conditions, as proposed by some authors ${ }^{14}$. However, the term NCSE has included patients ranging from those with barely detectable mental status changes to those in coma. Using this term indistinctly, we included forms that have easier control and different evolution in terms of morbidity and mortality. To minimize this confusion, we decided to use the term NCSE in coma and selected refractory cases.

In addition, a critical point, especially in our selection, needs to be discussed. From a clinical standpoint, any attempt to classify comatose NCSE has to answer some questions, and the most crucial is: does coma cause or become worse because of nonconvulsive seizure or NCSE, or by the underlying brain disorder itself? This is an unanswered question, once there are no valid criteria to differentiate the EEG patterns, which are directly related to status from other epiphenomenal electrical abnormalities caused by the underlying brain dysfunction ${ }^{14}$. It is worse when periodic patterns are included as an ictal one $\mathrm{e}^{15}$.

NCSE may be regarded as proven, if both the EEG and the clinical state are solved with antiepileptic drugs ${ }^{16}$. The reverse does not exclude an epileptic condition; otherwise, all refractory SE would have to be considered as nonepileptic, which is biologically not plausible ${ }^{17}$.

Discussion and definition are extremely important because of treatment and how aggressive it should be. This study had as main arm the ictal pattern and the outcome of cases that would not be considered as NCSE by some authors in the literature.

Regarding ictal pattern, Treiman ${ }^{18}$ described a sequential electroencephalographic evolution of SE, initially for convulse SE and then to secondary generalized SE. These patterns can be understood as a sequence of recurrent seizures, which at a given moment became continuous. Although there is no general consensus in the literature, several authors believe that, after a variable period, there may be progression to periodic or almost periodic activity representing the final stage of refractory complex partial $\mathrm{SE}^{19,20}$.

We believe that in refractory NCSE in coma, the electrographic findings are extremely varied and the epileptiform discharges are polymorphic, being possible the coexistence of sharp waves, spikes and poly-spikes mixed with slow waves of variable amplitude and in different topographies $^{12,13,18}$.

The most frequently initial ictal pattern observed in our series was DS, which occurred in half the cases as previously reported by Treiman et al. ${ }^{9}$ in experimental models and in patients with generalized convulsive SE as the initial pattern. In the same study, the authors demonstrated that PLEDs corresponded to the final stage of electrographic evolution in their patients with generalized convulsive SE. In contrast to this observation, $21.4 \%$ of our patients presented PLEDs as the initial ictal pattern, in agreement with the findings reported by Snodgrass et al. ${ }^{21}$, who detected PLEDs during the first four days of SE in some of the 147 patients reviewed by them.

We did not notice in our patients any stereotyped sequence of ictal patterns. On the contrary, the ictal patterns often alternated at random, with the coexistence of two others (DS and PLEDs) being actually observed in the same recording with a duration of approximately 30 minutes. This finding agrees with data reported by DelgadoEscueta et al. ${ }^{22}$, who stated that focal NCSE may be of a cyclic nature, both clinically and electrographically.

Periodic electrographic patterns have been described in a wide variety of neurological conditions, including structural and functional changes of the cerebral cortex, base ganglia, brain stem, and white matter ${ }^{18,20}$. However, although there is no general consensus, PLEDs are currently considered an ictal pattern by some investigators ${ }^{20}$. As previously demonstrated ${ }^{21,23,24}$, PLEDs are consistently related to poorer neurological prognosis and to higher morbidity and mortality. In the present study, all patients who presented this ictal pattern at some time during the course of their disease died during the acute phase of refractory complex partial SE.

We did not emphasize here aspects related to the morphology and frequency of epileptiform paroxysms, since, as previously demonstrated ${ }^{25}$, they do not vary significantly in patients with generalized or focal NCSE or generalized NCSE with focal accentuation, and do not make an effective contribution to the differential diagnosis between the different forms of SE.

In conclusion, the present data demonstrated that the electrographic findings of refractory complex partial SE are heterogeneous and do not follow a predetermined sequence. We also confirmed data reported by others showing that PLEDs are consistently related to poorer prognosis and higher mortality in refractory SE. The clinical and electrographic heterogeneity detected in cases of refractory complex partial SE explains the current controversies about the evaluation and classification of the ictal patterns of these patients. 


\section{References}

1. Gastaut H. Classification of status epilepticus. In: Delgado-Escueta AV, Wasterlain CG, Treiman DM, Porter RJ (Eds). Status Epilepticus. Mechanisms of brain damage and treatment. (Adv Neurol Vol. 34) New York: Raven Press; 1983:15-35.

2. Commission on Classification and Terminology of the International League Against Epilepsy. A proposed international classification of epileptic seizures. Epilepsia 1964;5:297-306.

3. Commission on Classification and Terminology of the International League Against Epilepsy. Proposal for revised clinical and electroencephalographic classification of epileptic seizures. Epilepsia 1981;22:489-501.

4. Lowenstein $\mathrm{DH}$, Bleck T, Macdonal RL. It's time to revise the definition of status epilepticus. Epilepsia 1999;40:120-122.

5. DeLorenzo RJ, Garnett LK, Towne AR, Waterhouse EJ, Boggs JG, Morton L, et al. Comparison of Status Epilepticus with prolonged seizure episodes lasting from 10 to 29 minutes. Epilepsia 1990;40:164-169

6. Guberman A, Cantu-Reyna G, Stuss D, Broughton R. Nonconvulsive generalized status epilepticus: clinical features, neuropysichological testing, and long-term follow-up. Neurology 1986;36:1284-1291.

7. Kaplan PW. Nonconvulsive status epilepticus. Semin Neurol 1996;16: 33-40.

8. Young GB, Jordan KG, Doig GS. An assessment of nonconvulsive seizures in the intensive care unit using continuous EEG monitoring: an investigation of variables associated with mortality. Neurology 1996;47:83-89.

9. Treiman DM, Walton NY, Kendrick C. A progressive sequence of electroencephalographic changes duriing generalized convulsive status epilepticus. Epilepsy Res 1990;5:49-60.

10. Gastaut H, Roger J, Roger A. Sur la signification de certaine fugies épileptiques. A propos d'une observation électrolinique d' "état de mal temporal". Rev Neurol 1956;94: 298-301.

11. Tomson T, Svanborg E, Wedlund J. Nonconvulsive status epilepticus: high incidence of complex partial status. Epilepsia 1986;27:276-285.
12. Gastaut H, Tassinari CA. Epilepsies. In: Rémond A (Ed). Handbook of electroencephalograph and clinical neurophysiology. Amsterdam: Elsevier; 1975:39-45

13. Treiman DM, Delgado-Escueta AV. Complex partial status epilepticus In: Delgado-Escueta AV, Wasterlain CG, Treiman DM, Porter RJ (Eds). Status epilepticus. Mechanisms of damage and treatment. (Adv Neurol; vol. 34) New York: Raven Press; 1983:69-81.

14. Brenner RP. EEG in nonconvulsive status epilepticus. J Clin Neurophysiol 1994;21:319-331.

15. Kaplan PW. The EEG of status epilepticus. J Clin Neurophysiol 2006;23:221-229

16. Kaplan PW.Behavioral manifestations of convulsive status epilepticus Epilepsy Behav 2002;3:122-139.

17. Bauer G, Trinka E. Nonconvulsive status epilepticus and coma. Epilepsia 2010;51:177-190.

18. Treiman DM. Electroclinical features of status epilepticus. J Clin Neurophysiol 1995;12:343-362.

19. Markland DW, Wheeler GL, Pollack SL. Complex partial status epilepticus (psychomotor status). Neurology 1978;28:189-196.

20. Garzon E, Fernandes RMF, Sakamoto AC. Serial EEG during human status epilepticus. Evidence for PLED as an ictal pattern. Neurology 2001;57:1175-1183

21. Snodgrass SM, Tsuburaya K, Ajmone-Marsan C. Clinical significance of periodic lateralized epileptiform discharges: relationship with status epilepticus. J Clin Neurophysiol 1989;6:159-172.

22. Delgado-Escueta AV, Boxley J, Stubbs N, Waddell G, Wilson WA. Prolonged twilight state and automatisms: a case report. Neurology 1974;24:331-339.

23. Cobb W, Hill D. Electroencephalogram in subacute progressive encephalitis. Brain 1950;73:392-404

24. Nei M, Lee JM, Shanker VL, Sperling MR. The EEG and prognosis in status epilepticus. Epilepsia 1999;20:157-163.

25. Granner MA, Lee SI. Nonconvulsive Status Epilepticus: EEG analysis in a large series. Epilepsia 1994;35:42-47. 